\title{
Calculating the Effect of Dispersion Wind Power Plants in the Electrical Network Reliability
}

\author{
Saeid Nahi \\ Department of Electrical \\ Engineering, Ilkhchi \\ Branch, Islamic Azad \\ University \\ Tabriz, Iran
}

\author{
Seyed M.H Nabavi \\ Department of Electrical \\ Engineering, Tabriz \\ Branch, Islamic Azad \\ University \\ Tabriz, Iran.
}

\author{
Aidin Sakhavati \\ Department of Electrical \\ Engineering, Tabriz \\ Branch, Islamic Azad \\ University \\ Tabriz, Iran.
}

\author{
S. Hajforoosh \\ Department of Electrical \\ Engineering, Damavand \\ Branch, Islamic Azad \\ University \\ Damavand, Iran.
}

\begin{abstract}
Demand for renewable energy in electric power systems is growing as fast. Reasons, including the desire of countries to increase production capacity of wind power are the great advantages of this method production of electrical energy. Because wind energy is many, renewable and clean.

The high penetration of renewable energy can reduce fuel costs, but can affect the electrical system reliability. Using probabilistic methods, and estimates can be combined to achieve high reliability in the electrical system is combined with new energy.

In this article, the reliability of power delivery is calculated and reduced network load caused a definite increase in the dispersion of wind power plants has been studied using Monte Carlo simulation method.

In this paper, collect data on wind speed of wind sites in Binalood and Manjil areas in Iran have a minute, and over the years have been doing. Simulations based on Monte Carlo method and frequency, and is performed using softwares Matlab and Excel. And reliability indices and algorithms based on the calculated reliability indices LOLE and LOEE are performed.
\end{abstract}

\section{Keywords}

Wind turbine, Reliability, Dispersion, Monte Carlo, Renewable Energy.

\section{INTRODUCTION}

In this paper, the small wind turbo generators are compared with diesel generators.

Cost and benefit analysis should be done carefully in order to install the appropriate resources. Installation of renewableenergy sources can enhance the system capacity and reduce fuel costs [12]. Techniques require reliable information on weather conditions, storage, load profiles, system generation and auxiliary systems.

This paper examines the effect of scattering in the wind power plants will increase system reliability [10].

Different parts of the paper are organized as follows. The concept of a safe and reliable production system is presented in section 2. Section 3 shows the properties of air which are used in the study. Section 4 explains how the model can produce wind turbines. Obtained results using wind turbines are presented in section 5. Used load profiles in the experiments are shown in section 6. Section 7 shows the types of dispersed wind models that are used in this study.
In the presented method, the number of wind turbines considering for wind power plants with wind-climate regions is optimized.

Information on wind speed of the region in Binalood and Manjil in Iran is used. Applications and measures wind speed over the years has been used for a minute. As well as computational simulations based on Monte Carlo simulations have been performed.

\section{THE CONCEPT OF A SAFE AND UNSAFE ELECTRIC SYSTEM}

When the system is in a good condition, it means that the amount of renewable energy is needed once more. That means half of the area of renewable energy is less than the amount of loads, it needed help, and storage systems may have to recover needed load. Furthermore when the system is at risk meant that the amount of wind-power generation and auxiliary systems required response load are not spheres. Different modes are shown in Figure 1 [1], [8].

The following factors are used to calculate the adequacy of wind systems:

- The local weather conditions and wind.

- The generation of windy system.

- The generation of other auxiliary systems

- The requested load demand

These factors will explain in details in the next parts of article.

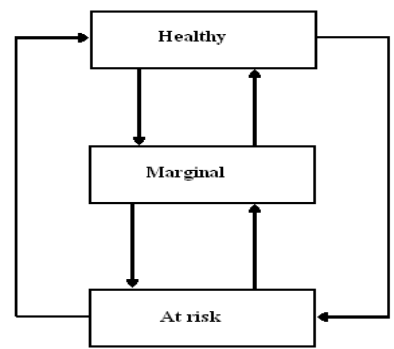

Fig 1: A variety of possible conditions for a generation system

\section{SURVEY CLIMATE ZONES}

Figure 2 and Figure 3 show the average annual change in wind during the day in Binalood and Manjil wind areas. It can be seen that between 11 o'clock to 21 o'clock the wind speed is higher than others. Resulting in wind power production in hours will be mentioned further. 


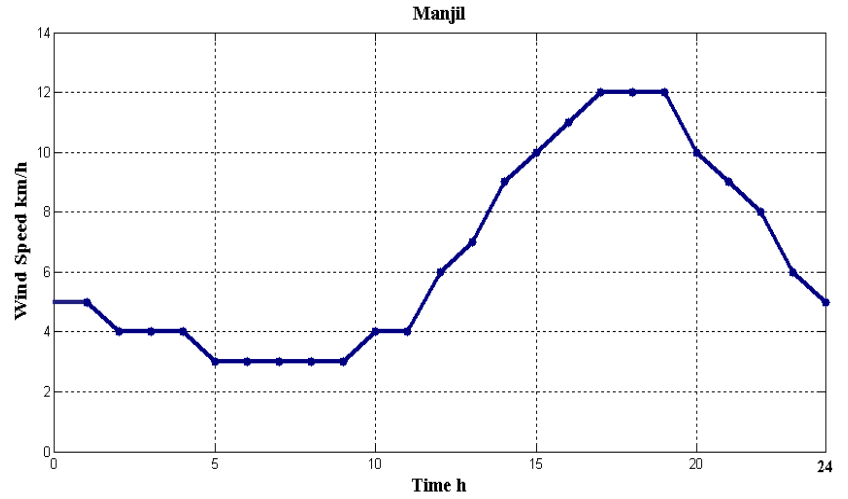

Fig 2: Average annual change in the wind during the day as Manjil

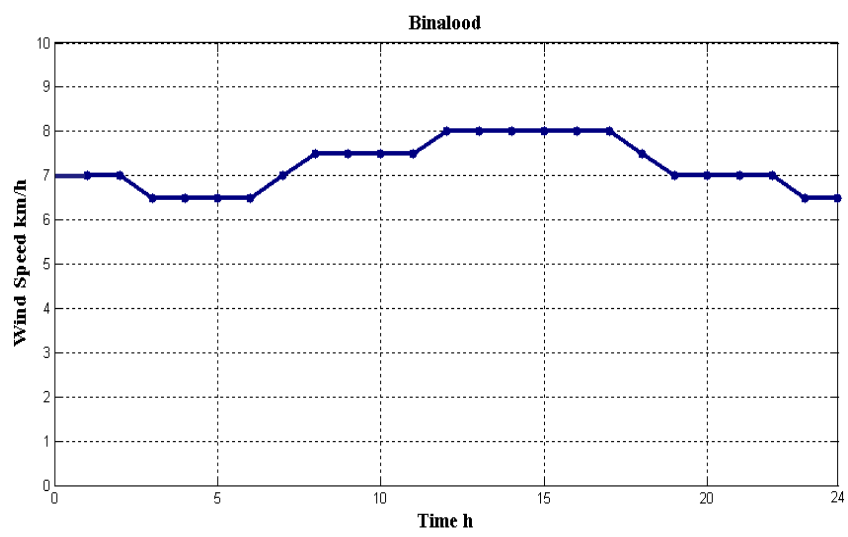

Fig 3: Average annual change in the wind during the day as Binalood

Probability distributions of wind speeds for different hours are drawn from these charts. It should be noted that for the wind speeds which are less than $6 \mathrm{~m} / \mathrm{sec}$ the probability is moderated. Furthermore, for wind speeds between $6 \mathrm{~m} / \mathrm{sec}$ to $15 \mathrm{~m} / \mathrm{sec}$ the probability is high, and for higher wind speeds than $15 \mathrm{~m} / \mathrm{sec}$ the probability the least likely event during the year.

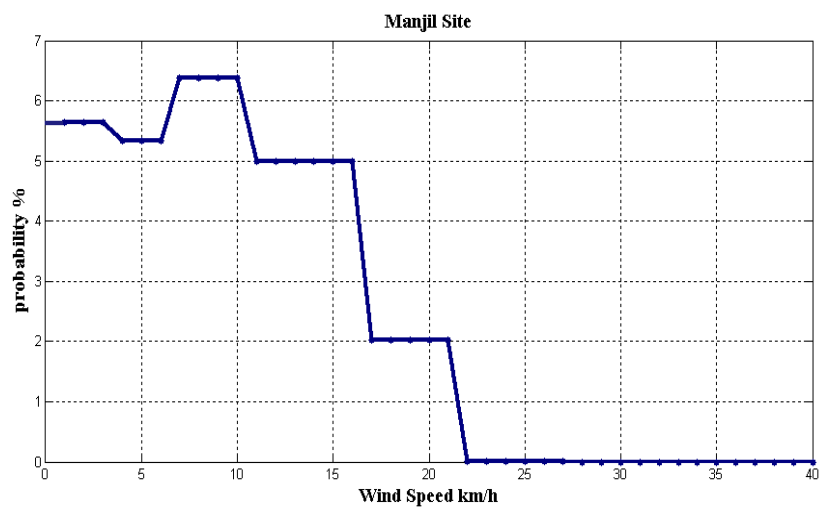

Fig 4: Percent chance of wind at different speeds as the Annual Manjil area

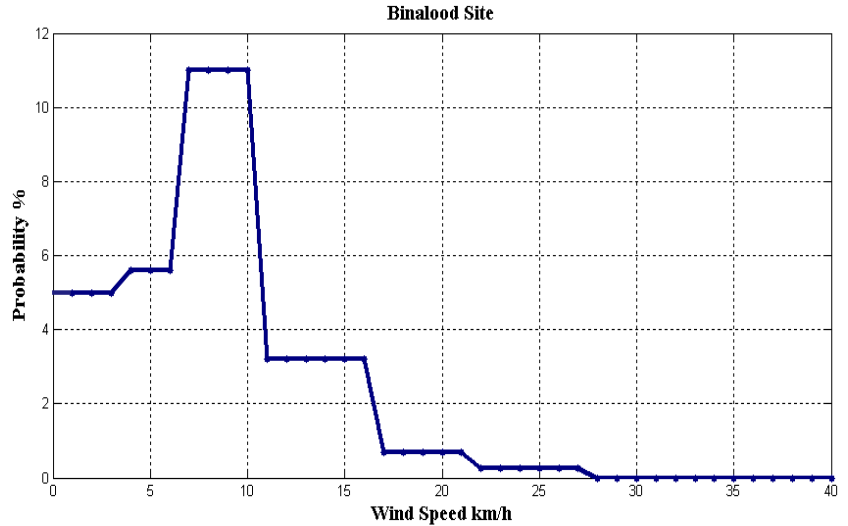

Fig 5: Percent chance of wind at different speeds as the Annual Binalood area

\section{WIND TURBINE MODELING}

In this paper, the amounts of wind turbines' generations are calculated as follows:

$$
P\left(S W_{t}\right)=\left\{\begin{array}{lr}
0 & 0 \leq S W_{t} \leq V_{c i} \\
\left(A+B+S W_{t}+C \times S W_{t}^{2}\right) \times P_{r} & V_{c i} \leq S W_{t} \leq V_{r} \\
P_{r} & V_{r} \leq S W_{t} \leq V_{c o} \\
0 & S W_{t} \leq V_{c o}
\end{array}\right.
$$

where $S W_{t}, P_{r}, V_{c i}, V_{r}$ and $V_{c o}$ include wind speed, maximum power generation, wind cut input speed, wind rated speed and wind cut output speed respectively. The constants A, $\mathrm{B}$ and $\mathrm{C}$ are related to above through the following equations can be calculated as follows:

$$
\begin{aligned}
& A=\frac{1}{\left(V_{c i}-V_{r}\right)^{2}}\left\{V_{c i}\left(V_{c i}+V_{r}\right)-4 V_{c i} V_{r}\left[\frac{V_{c i}+V_{r}}{2 V_{r}}\right]^{3}\right\} \\
& B=\frac{1}{\left(V_{c i}-V_{r}\right)^{2}}\left\{4\left(V_{c i}+V_{r}\right)\left[\frac{V_{c i}+V_{r}}{2 V_{r}}\right]^{3}-\left(3 V_{c i}+V_{r}\right)\right\} \\
& C=\frac{1}{\left(V_{c i}-V_{r}\right)^{2}}\left\{2-4\left[\frac{V_{c i}+V_{r}}{2 V_{r}}\right]^{3}\right\}
\end{aligned}
$$

Figure 6 shows the relationship between Pr, Vci, Vr and Vco chart diagram which is called as Power Curve (diagrams power speed).

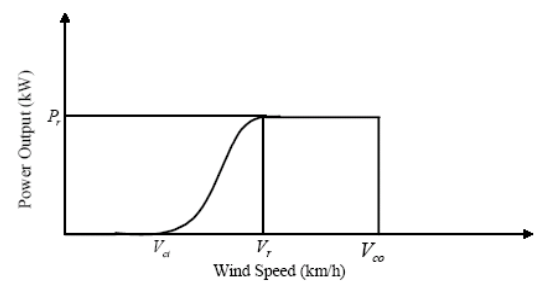

Fig 6: Changes output power to wind speed in wind generator

\section{CALCULATION RESULTS}

Relationships with the sector 3-3 for wind power production in Manjil and Binalood chart average annual Day of the figures (7) and (8) and $660 \mathrm{~kW}$ turbines can produce different values in the areas listed in Figure (9) and (10) is shown. In the diagram (7) and (8) vertical axis represents the average probability of 
producing a maximum production capacity of $660 \mathrm{~kW}$ turbines is the horizontal axis represents time, and the day is over. It can be seen in the afternoon the wind turbines produce 11 to 22 is the maximum wind speed is high.

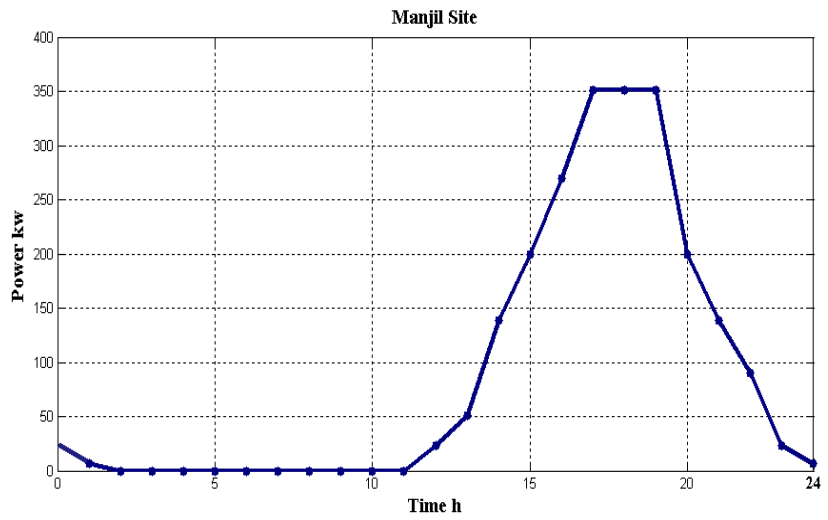

Fig 7: Average 660kw turbines produce power during the day in Manjil

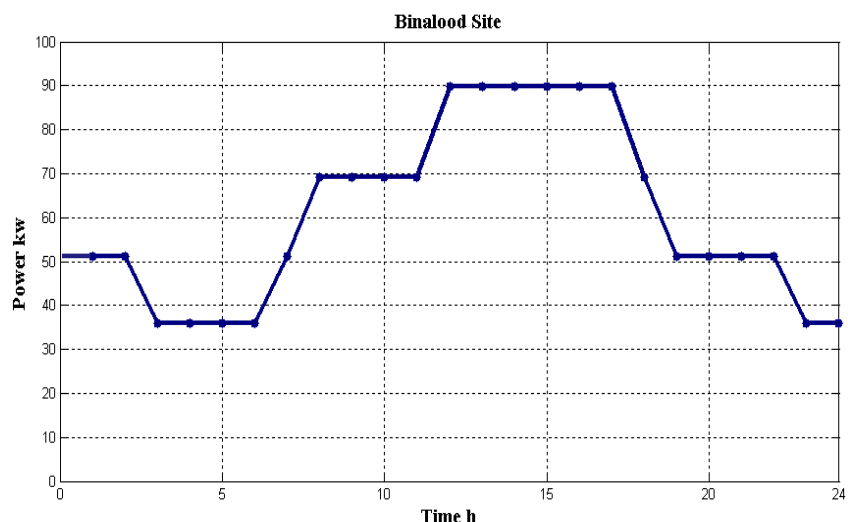

Fig 8: Average 660kw turbines produce power during the day in Binalood

In Figure 9 and 10 percent probability of producing wind turbines based on their respective power output is displayed. As can be seen in both the wind power production to zero, respectively, of between $50 \mathrm{~kW}$ to $250 \mathrm{~kW}$ and above $660 \mathrm{~kW}$ have the highest risk.

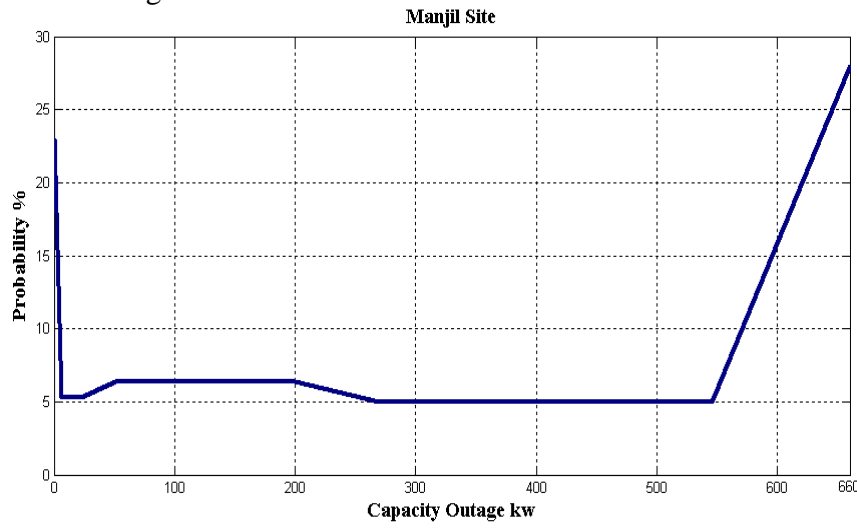

Fig 9: Percent chance of producing turbines in Manjil

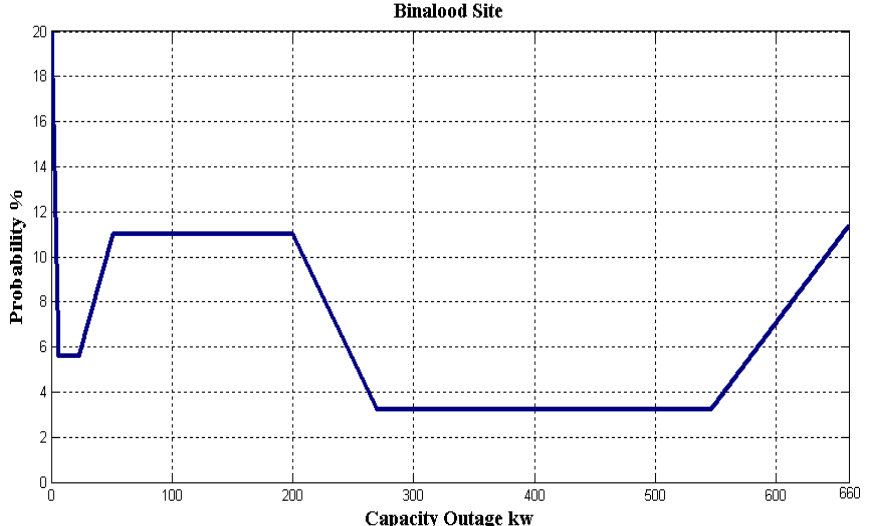

Fig 10: percent chance of producing wind turbine in Binalood

\section{LOAD PROFILES USED IN THE EXPERIMENTS}

Precision measurements at a load during the year have been made. Weekly basis in the figure (11), the annual basis in the figure (12) and the load continues curve as in the one year in figure (13) is shown.

The results of the figure 11 is found to be the minimum amount of hourly load is in the night clocks. And days of week in holiday and weekend day due to the closure of many factories and offices may be less.

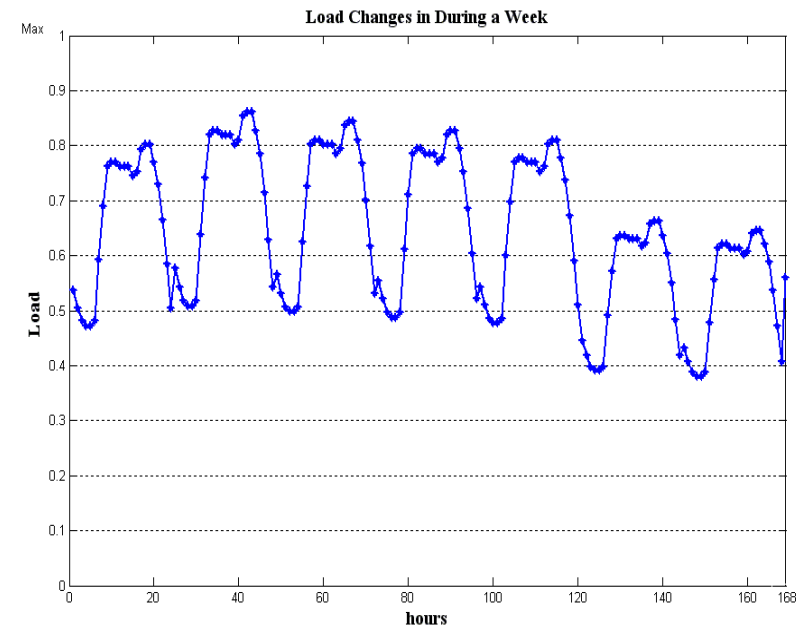

Fig 11: Example of load changes in during a week

In figure 12 minutes of the load demand during the year as is customary. As can be seen in some seasons the average load for reasons including the need to reduce heating and cooling systems, changes in day length, cultural issues in different geographical regions and different countries to reduce or increase. 


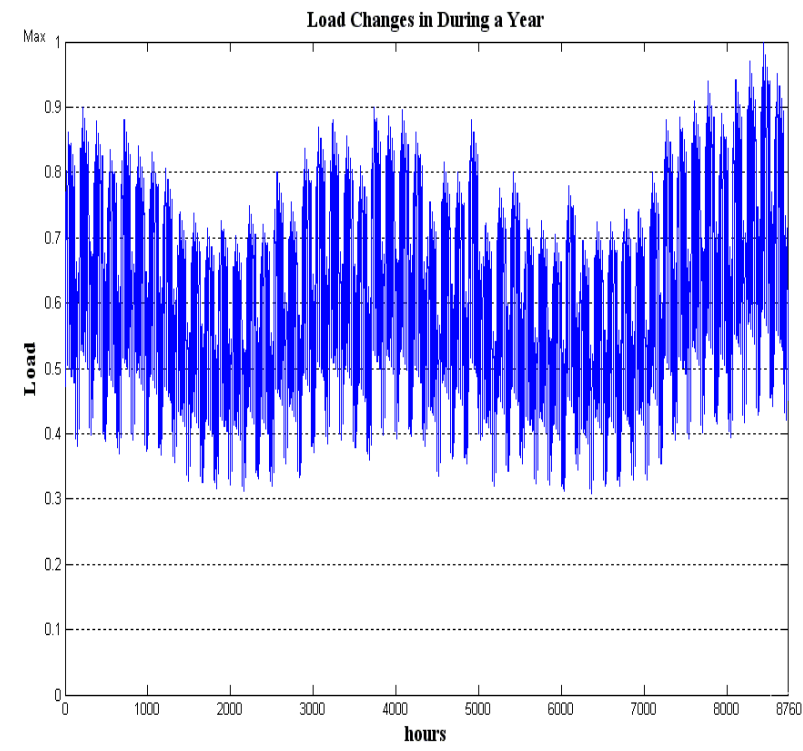

Fig 12: Load changes in during a year

Figure 13 shows the total one year time in horizontal axis and vertical axis are the percentage of load demand. As can be seen at least $40 \%$ loads always in demand is constant and close to $100 \%$ loads is the minimum length of time are allocated to demand.

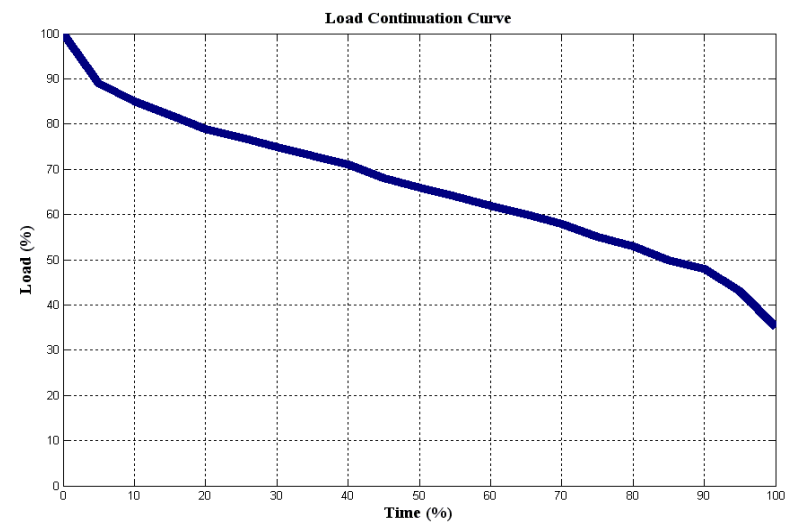

Fig 13: The load continuation curve

\section{SHOW THE TYPES OF DISPERSED WIND MODELS USED IN THIS STUDY}

Profile of wind areas that have been added to the system include:

The first model - one wind region with a capacity of $100 \mathrm{MW}$ The second model - two wind region with a capacity of $50 \mathrm{MW}$ The third model - three wind region with a capacity of $33 \mathrm{MW}$ The fourth model - four wind region with a capacity of $25 \mathrm{MW}$ Computer program was written so that if a certain period of time (LOLE) and the amount of energy not supplied to the load (LOEE) limit of $10 \%$ and $420 \mathrm{MWh} / \mathrm{yr}$ generates a new wind capacity added to the system and test again is repeated, resulting in a new value for the total system capacity is achieved.

Simulations have been conducted according to the following assumptions:

1 - Capacity of a wind turbine have been considered is $1 \mathrm{MW}$.

2 - Probability force out of rate the capacity of each wind turbine (FOR) is equal to 0.04 .

Blocks of different modes of dispersion used in this study in figure 14 is drawn.

\section{CALCULATION THE RELIABILITY INDICES LOLE AND LOEE}

Reliability has been calculated in detail in this section.

\subsection{Monte Carlo Simulation Method}

As we the reliability wind power output units are associated with changes in wind and FOR but diesel power output only associated with FOR. Hence, the probability of exit capacity (copt) The power must be achieved using Monte Carlo methods for index, then it must be considered. Monte Carlo simulation of that work are as follows:

Using information about song damage $\lambda$ and song repair $\mu$ each unit, units status for one year is determined.

$T T F_{i}=-\operatorname{Ln}(U) / \lambda_{\mathrm{i}}$
$T T R_{i}=-\operatorname{Ln}(U) / \mu_{\mathrm{i}}$

$T T F_{i}$ : Long waiting time for unit i is a failure.

$T T R_{i}$ : Long waiting time for unit i is repaired.

$U$ : Uniform random number between zero to one 


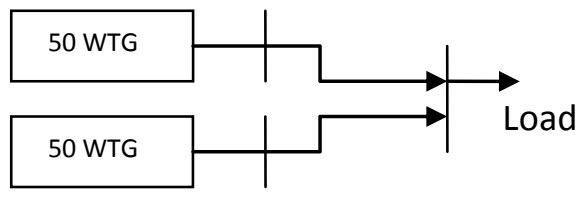

Model 2: Two distinct windy regions with $50 \mathrm{~kW}$ each region capacity and a $100 \mathrm{~kW}$ total of wind production capacity

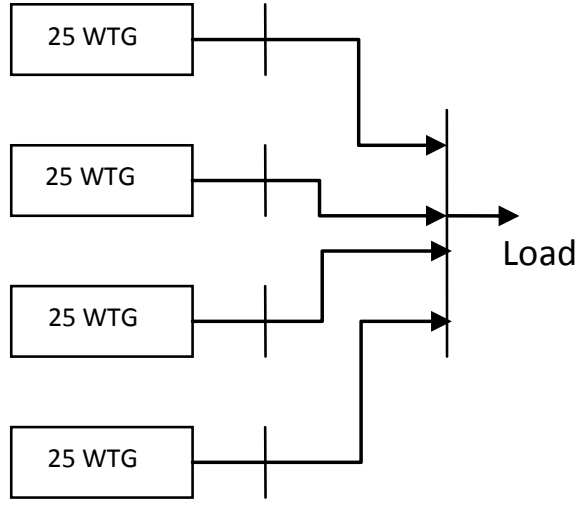

Model 4: Four distinct windy regions with $25 \mathrm{~kW}$ each region capacity and a $100 \mathrm{~kW}$ total of wind production capacity

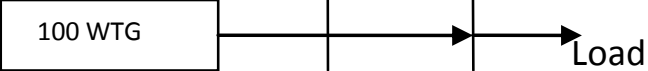

Model 1: One windy region with $100 \mathrm{~kW}$ total of wind production capacity

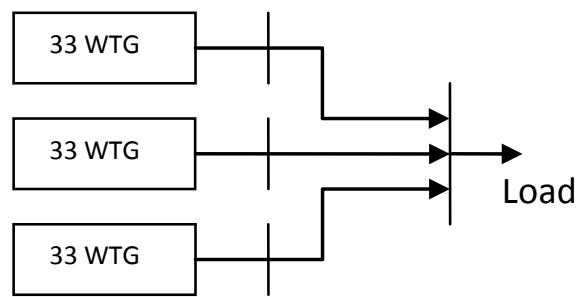

Model 3: Three distinct windy regions with $33 \mathrm{~kW}$ each region capacity and a $100 \mathrm{~kW}$ total of wind production capacity

Fig 14: View dispersion models used in the study (one, two, three and four regional)

Beginning in the simulation all units is active. Producing uniform random number will be determined by $T T F_{i}$ units, passed with the time unit is removed from the circuit. To determine the expected repair time production $T T R_{i}$ random number will be determined by that time passed with this unit is back on the circuit. The process according to figure 15 where the unit status during the year ( 8760 hours) simulation will be continued.

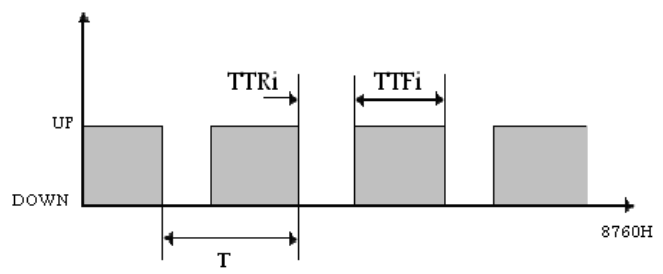

Fig 15: Status modeling unit i during the year

\subsection{Calculation of a Definite Amount of Time and Energy not Supplied to the Load}

Indicators used in this study are as follows.

LOLE: Loss of Load Expectation (hrs / year)

LOEE: Loss of Energy Expectation (MWh / year)

In this part of the program by visiting the load sub-models and capacity plans (previously marked) and using a series of uniform random numbers that are written in a minor amount of LOLE values decisive occurred the percentage, in units (hour/year) and (day/year) and LOEE calculated in terms of energy lost as a result of the number is distinct and printed.

Program general principles of the figure 16 this is the time for a move that represents the maximum amount of load hours in a day or a year (depending on what day load curve of day or load continuation curve is used). If we use the continuity of the curve should be through out the possibility of generating capacity, we calculate the reliability indices. In a method that we will use this article was using daily load curve that by using time daily load changes curve and determining the amount of production by accident by using the algorithm and presented in this section of the index of the ability to calculate that we will.

In other words, with generating random numbers and map them out on the productive capacity probability a variable that represents the capacity available on that day or hour (for the maximum load) is achieved. When comparing these two values obtained (load and capacity) if the amount is less than the load capacity is determined by a lack of load to be otherwise at this stage (days or hours), lack of time will not.

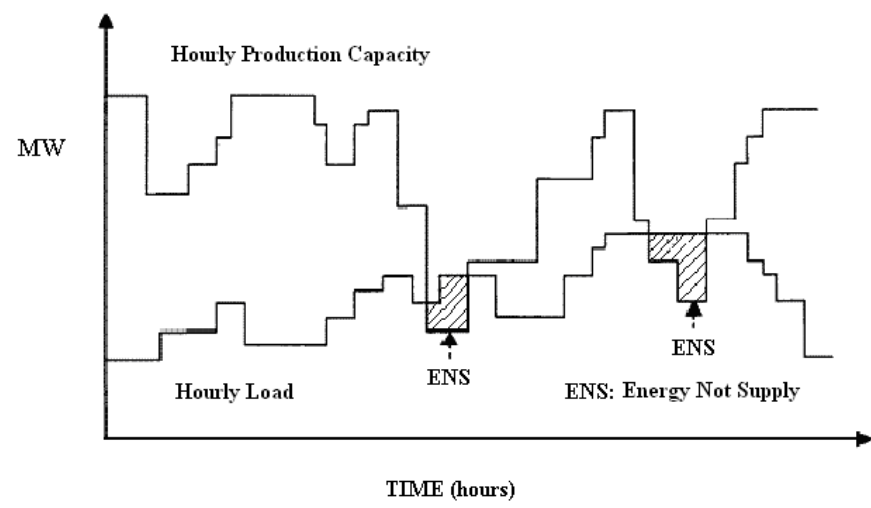

Fig 16: View load changes and electric energy production

This cycle is repeated many times and the average loss, lack of energy and calculate the exact number in a year index LOEE and LOLE values are obtained. Different stages of the program are stated in section 8.3. 


\subsection{Algorithm Simulation}

Simulation algorithm in Figure (17) is drawn. The algorithm measures the reliability of wind power plants (LOEE, LOLE) is calculated in terms of network connectivity.

The algorithm variables are defined as follows:

$\mathrm{n}$ : Number of repeat tests

NUMSIM: number of years of repeated testing

LOLE: loss of load expectation (hrs/year)

LOEE: loss of energy expectation (MWh/year)

h: Time of year (hr)

L: Load proportional to the time (watt)

D: Diesel production capacity (watt)

B: Capacity of wind (watt)

P: A moment of total production capacity of diesel and wind (watt)

Different stages of the simulation algorithm are as follows:

Step 1

A - Specifies the number of repeated simulations

B - Reception information of load in during a year

C - Get the power generation capacity and diesel units FOR

D - Get information of wind speed areas, the number of turbines and wind turbine production capacity in each region.

Step 2

A - Mapping hour on the load requested curve

B - Generate a random number for the mapping of wind curve on the annual wind speed with using Monte Carlo simulation

$\mathrm{C}$ - Mapping the random number on the annual production of the wind and find the moment wind turbine generating

D - Generate a random number for mapping onto the diesel unit generate with using Monte Carlo simulation

E - Mapping the random number on the characteristic diesel generating units and find the moment generating units of diesel

F- The calculation of wind power production units

$\mathrm{G}$-Calculate the total of wind and diesel power units

Step 3

Compared the total amount of load required to be total electric produced

Step 4

In case of shortage, calculate reliability indices of LOLE and LOEE

Step 5

Continue steps 2 to 4 to complete year

Step 6

Repeat steps 2 to 5 in order to increase the accuracy of the experiment and then averaging the results In addition to the above characteristics have been drawn to the following algorithm can also be noted.
1 - This algorithm is implemented for all areas simultaneously.

2 - The total production capacity of wind turbines power should be considered in all areas.

3 - Likely out of the capacity of individual turbines and repair time, while the simulation is considered.

4 - In order to increase accuracy and to minimize the deviation of the experimental results, the whole process to simulate the high frequency of about four million times by high speed computers has been done, and then average the results have been taken.

Flow chart of the program in figure 17 is shown.

\section{RESULTS OF THE RELIABILITY OF WIND POWER STATIONS COMPUTING IN VARIOUS MODELS OF DISTRIBUTED}

One of the important points in the increasing capability wind power plants that is distribution of development in many geographical regions that this is because of fluctuations closer to producing electrical energy amount to an average, will increase the capacity confidence in the system.

In this study we aim to fix the LOLE values below $10 \%$ and LOEE values below $420(\mathrm{MWh} / \mathrm{yr})$ and find out how much production is needed in each of the models. As shown in Figure 18 we see to achieve these levels of reliability through the algorithms and methods are presented in Section 8 in models 1, 2, 3 and 4 of the wind in order to install $600 \mathrm{MW}, 550 \mathrm{MW}, 350 \mathrm{MW}$ and $250 \mathrm{MW}$ is done.

The study results can be seen wind capacity needed for a system 4 regional to reach the ability to make sure ideal almost a third a regional system. In other words if two wind production system to consider as total capacity of wind have been installed in each of the two systems have been times but the number of areas they are not equal in this case capacity system that every one of the regions with the wind capacity system units smaller than the other, a reliability will be better.

As the results are calculated and figures is shown with several part of wind turbine areas of wind production an economy in the total number of the turbines needed can be achieved.

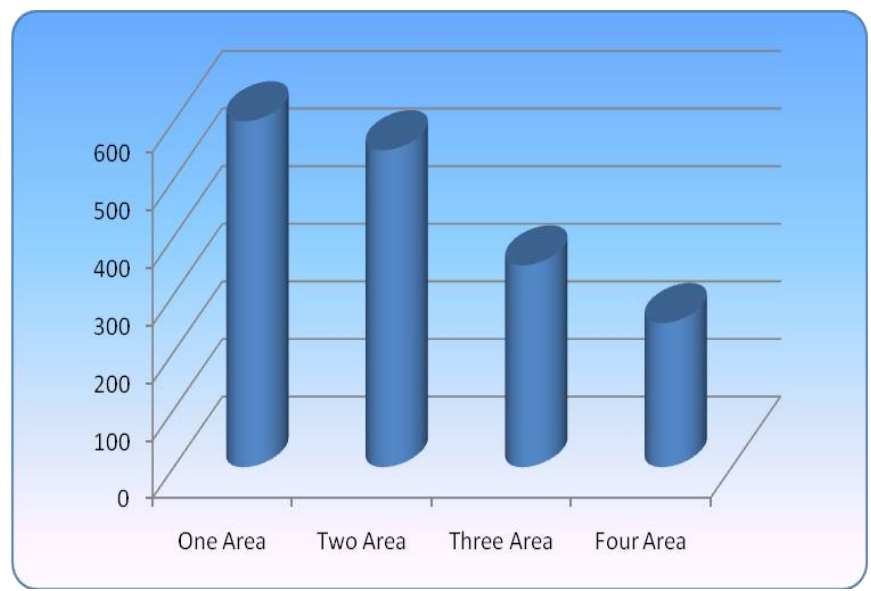

Fig 18: Results of calculations of wind capacity needed to achieve LOLE below $10 \%$ and LOEE below $420(\mathrm{MWh} / \mathrm{yr})$ in areas of wind $1,2,3$ and 4 regional 


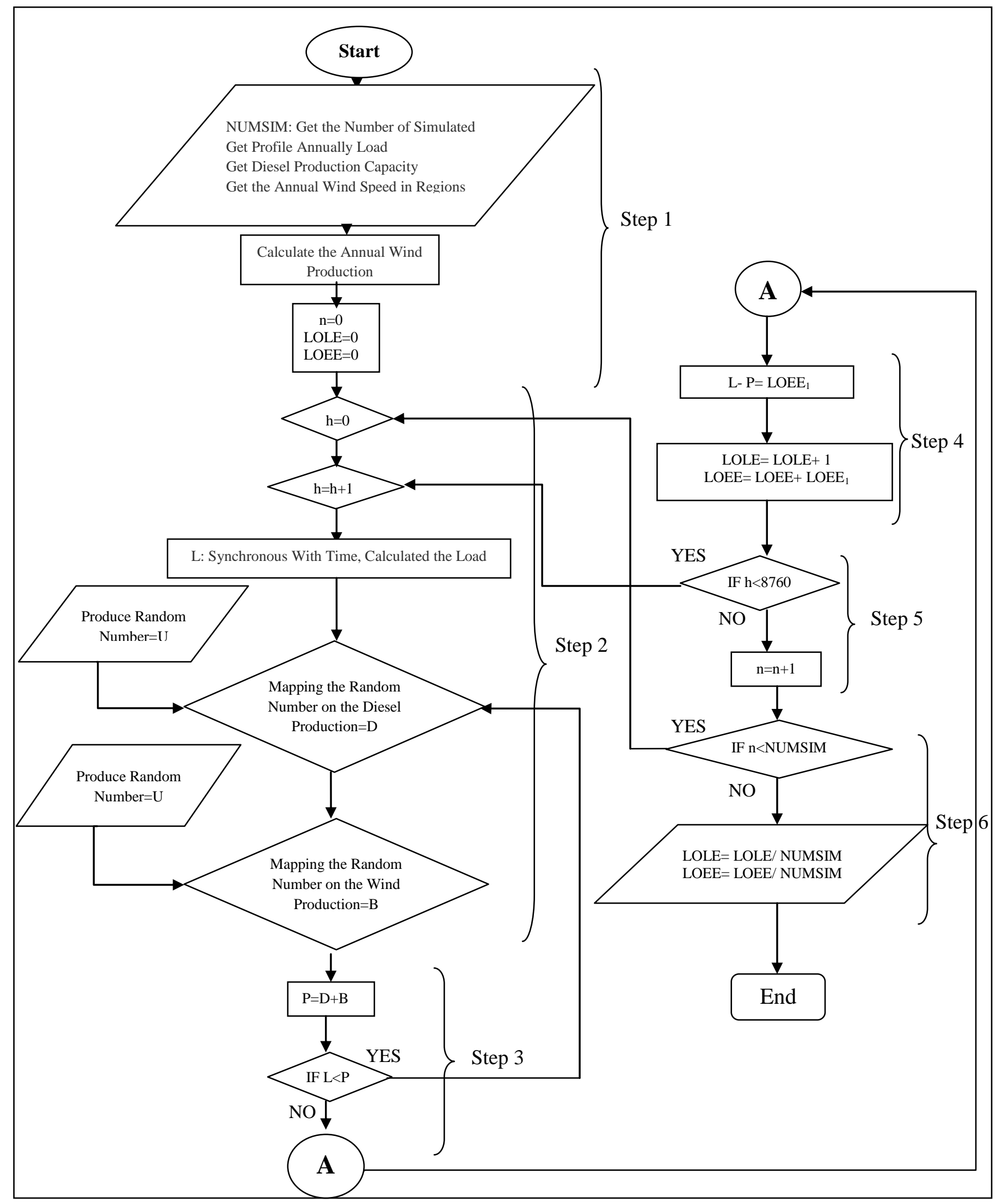

Fig 17: Flowchart of simulation program for calculate reliability indices LOLE and LOEE 


\section{CONCLUSIONS}

This paper examines ways to increase contributed wind power plants to the national network by increasing the dispersion of wind systems using algorithms and Monte-Carlo simulation method for calculating wind paid to main grid systems. Computing the reliability indices LOLE and LOEE indicators were specifically included. And the effect of wind plant on the distribution system reliability indices were noted.

Part of the various stages of the articles included: first to receive information wind annually, the annual demand for network and normal annual production network in near Manjil and Binalood wind areas we dealt with Iran, then by using the calculation has been mentioned in the section 3 can be calculated according to the wind turbines production based on the amount of wind speed discussed and then using the algorithm presented in Section 8, and considering the possibility of failure and the time needed to return power to the circuit to help calculate the amount of plant antibodies to the network to reduce the number of times and definitely not providing the energy needed for the exchange of four types of wind models a year paid.

Important indicators of wind turbines that were effective in this study were: 1 - The maximum turbine power production $\left(\mathrm{P}_{\mathrm{r}}\right), 2$ - Wind cut input speed $\left(\mathrm{V}_{\text {Cut In }}\right), 3$ - Wind Rated Speed $\left(\mathrm{V}_{\text {Rated }}\right.$ Speed $), 4$ - Wind cut output speed $\left(\mathrm{V}_{\text {Cut Out }}\right)$

Some of the results of this study can be summarized as follows:

1 - Wind capacity reduction needed to be installed in the in scattered wind areas, simply to see half of the amount of the need for the wind turbines in regional 4 model.

2 - Increase the reliability rate of nearly 3 times only with increase the number of wind areas to 4 number and keeping constant the number of wind turbines

3 - To explore potential wind areas for wind power plants

4 - Offering algorithms and methods for calculation of reliability indices presented in this paper were the LOLE and LOEE

5 - Increase the reliability of electrical systems in combination with renewable energy with a fixed total number of wind turbines

6 - And also a number of reasons can reduce or increase the production systems that are related to the parameters evaluated in this study to detect.

In other words with method has been presented in this article we can instead of increasing the number of wind turbines and increasing the costs for buying and installing wind turbines by choosing the building place and setting the proper in installing wind turbines with regard to the status of atmospheric wind areas, choose a place for optimal geography, economy in the number of turbines and consequently increase system electric capacity We have confidence.

\section{ACKNOWLEDGMENTS}

Hereby commend and thank the authors of the Ilkhchi branch Islamic Azad University for financial support of this research project and plan are reported.

\section{REFERENCES}

[1] R . Billinton, R. N. Allan ,"Reliability Evaluation of Engineering Systems", 2nd Edition, Plenum Press, New York, 1992.

[2] Nick Jenkins, Ron Allan, Peter Crossley, Daniel Kirschen and Goran Strbac, "Embedded generation", The Institution of Electrical Engineers, London, United Kingdom, 2000.

[3] Pudaruth, G.R.; Furong Li;"Locational Capacity Credit Evaluation", Power Systems, IEEE Transactions on 2009.

[4] Nahi, S. And Nabavi, S, M, H." Choose Suitable Wind Turbines for Manjil Wind Power Plant using Monte Carlo Simulation" IJCA International Journal of Computer Applications, USA Vol. 15, No. 1, 2011.

[5] Robb, D "Starting up to Transmition Reliability Standards", Power Engineering International (PEi). Vol 12, Issue 2, February 2004.

[6] De Azua. C.R, "Growth in Worldwide and United States Wind Generating Capacity as Compared With Nuclear Capacity", Wind Engineering, U.K., vol 24, no.6, pp. 455458.

[7] Nahi, S." Load Forecasting on Special Days \& Holidays in Power Distribution Substation Using Neural \& Fuzzy Networks", IEEE International on Computational Intelligence for Modeling Control and Automation, Australian Conference,2006.

[8] Yuping Lu, Xin Yi, Ji'an Wu, Xia Lin, “An Intelligent Islanding Technique Considering Load Balance for Distribution System with DGs", IEEE, 2006, pp. 567-573.

[9] Jun Y., Liuchen C. and Diduch C., "Recent developments in islanding detection for distributed power eneration," IEEE, Large Engineering systems Conference, pp. $124-128$, 28-30 July, 2004.

[10] E. Muljadi, C.P. Butterfield, " Power quality aspects in a wind power plant " IEEE 2006, Power Engineering Society General Meeting.

[11] Gianfranco Chicco, Paolo Di Leo, " Experimental analysis of wind farms connected to the high voltage grid : the viewpoint of power quality " , First international Symposium on volume, Issue, July 2006 page(s): 184 189.

[12] Nahi, S. And Nabavi, S, M, H.” Estimated Production Potential Types of Wind Turbines Connected to the Network Using Random Numbers Simulation" WASET World Academy of Science, Engineering and Technology, UAE Conference, 2011.

[13] Nabavi. S. M. H, Khafafi. K, Sakhavati. A, And Nahi. S,:"Optimal Locating and Sizing of SSSC Using Genetic Algorithm in Deregulated Power Market" IJCA International Journal of Computer Applications, USA Vol. 22, No. 4, 2011. 
[14] Nahi. S, Hajforoosh. S, And Nabavi. S. M. H," Automation System Software and Dispatching of Electricity Networks" International Review on Modelling and Simulations, August 2011 Vol. 4. n. 4 pp. 1781-1790.

[15] Billinton. R., Chen. H, and Ghajar, R,:"A sequential simulation technique for adequacy evaluation of generating systems including wind energy", IEEE Transactions on Energy Convertion, Vol. 11, No. 4, December 1996.

[16] Francois. Giraud, Zyiad. M. Salameh,:"Steady-State performance of a grid-connected rooftop hybrid WindPhotovoltaic power system with battery storage", IEEE
Transactions on Energy Conversion, Vol. 16, No. 1, March 2001.

[17] Billinton. R., Bagen,:'Incorporating reliability index distributions in small isolated generating system reliability performance assessment", IEE Proc.-Gener. Transm. Distrib., Vol. 151, No.4, July 2004.

[18] Karki. Rajesh, Billinton. Roy,:"Considering renavable energy in small isolated power system expansion ",CCECE 2003-CCGEI 2003, Montreal, 2003 IEEE. 